University of Wollongong

Research Online

Faculty of Engineering - Papers (Archive)

Faculty of Engineering and Information

Sciences

$1-1-2012$

\title{
Electrical and thermoelectric properties of single-wall carbon nanotube doped Bi2Te3
}

\author{
Y Zhang \\ University of Wollongong \\ Xiaolin Wang \\ University of Wollongong, xiaolin@uow.edu.au \\ W K. Yeoh \\ University of Sydney \\ R K. Zeng \\ University of Sydney, rzeng@uow.edu.au \\ C Zhang \\ University of Wollongong
}

Follow this and additional works at: https://ro.uow.edu.au/engpapers

Part of the Engineering Commons

https://ro.uow.edu.au/engpapers/5234

\section{Recommended Citation}

Zhang, Y; Wang, Xiaolin; Yeoh, W K.; Zeng, R K.; and Zhang, C: Electrical and thermoelectric properties of single-wall carbon nanotube doped Bi2Te3 2012.

https://ro.uow.edu.au/engpapers/5234

Research Online is the open access institutional repository for the University of Wollongong. For further information contact the UOW Library: research-pubs@uow.edu.au 


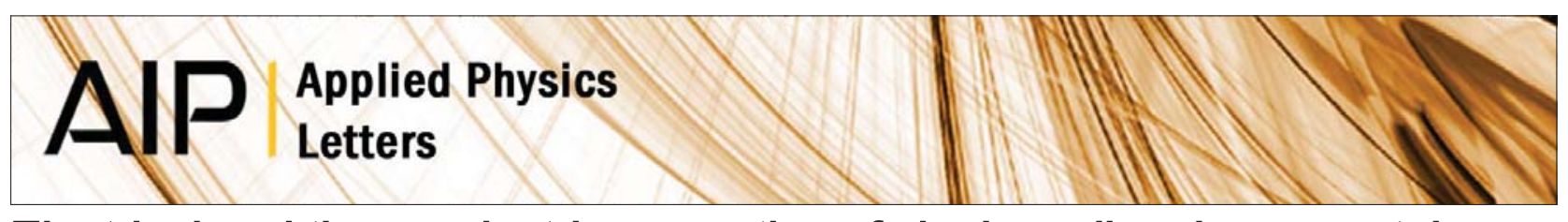

\section{Electrical and thermoelectric properties of single-wall carbon nanotube doped $\mathrm{Bi} 2 \mathrm{Te} 3$}

Y. Zhang, X. L. Wang, W. K. Yeoh, R. K. Zeng, and C. Zhang

Citation: Appl. Phys. Lett. 101, 031909 (2012); doi: 10.1063/1.4737898

View online: http://dx.doi.org/10.1063/1.4737898

View Table of Contents: http://apl.aip.org/resource/1/APPLAB/v101/i3

Published by the American Institute of Physics.

\section{Related Articles}

Thermal stability of thermoelectric materials via in situ resistivity measurements Rev. Sci. Instrum. 83, 115114 (2012)

A proposal for time-dependent pure-spin-current generators Appl. Phys. Lett. 101, 213109 (2012)

Detrimental influence of nanostructuring on the thermoelectric properties of magnesium silicide J. Appl. Phys. 112, 093716 (2012)

Comparison of thermoelectric properties of p-type nanostructured bulk Si0.8Ge0.2 alloy with Si0.8Ge0.2 composites embedded with $\mathrm{CrSi} 2$ nano-inclusisons

J. Appl. Phys. 112, 093714 (2012)

Disordered stoichiometric nanorods and ordered off-stoichiometric nanoparticles in n-type thermoelectric Bi2Te2.7Se0.3

J. Appl. Phys. 112, 093518 (2012)

\section{Additional information on Appl. Phys. Lett.}

Journal Homepage: http://apl.aip.org/

Journal Information: http://apl.aip.org/about/about_the_journal

Top downloads: http://apl.aip.org/features/most_downloaded

Information for Authors: http://apl.aip.org/authors

\section{ADVERTISEMENT}

\section{MP Applied Physics Letters}

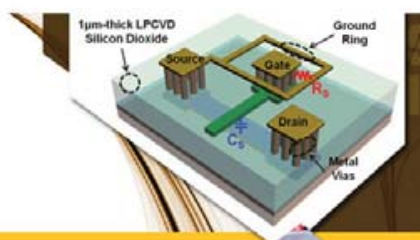

SURFACES AND INTERFACES

Focusing on physical, chemical, biological, structural, optical, magnetic and electrical and more.

\section{EXPLORE WHAT'S NEW IN APL}




\title{
Electrical and thermoelectric properties of single-wall carbon nanotube doped $\mathrm{Bi}_{2} \mathrm{Te}_{3}$
}

\author{
Y. Zhang, ${ }^{1}$ X. L. Wang, ${ }^{1, a)}$ W. K. Yeoh, ${ }^{2}$ R. K. Zeng, ${ }^{2}$ and C. Zhang ${ }^{1,3, b)}$ \\ ${ }^{1}$ Institute for Superconducting and Electronic Materials, University of Wollongong, NSW 2522, Australia \\ ${ }^{2}$ Australian Centre for Microscopy and Microanalysis, University of Sydney, NSW 2220, Australia \\ ${ }^{3}$ School of Physics, University of Wollongong, NSW 2522, Australia
}

(Received 13 March 2012; accepted 5 July 2012; published online 18 July 2012)

\begin{abstract}
The effects of single-wall carbon nanotube (SWCNT) doping in $n$-type $\mathrm{Bi}_{2} \mathrm{Te}_{3}$ bulk samples on the electrical and thermal transport properties have been studied. $\mathrm{Bi}_{2} \mathrm{Te}_{3}$ samples doped with $0-5 \mathrm{wt}$. \% SWCNTs were fabricated using solid state reaction and investigated using x-ray diffraction, transmission electron microscopy, and magneto transport measurements. Results show that the $0.5 \%$ doping results in the significant enhancement of the Seebeck coefficience to as high as $-231.8 \mu \mathrm{V} / \mathrm{K}$, giant magneto resistance of up to $110 \%$, reduction of thermal conductivity, and change of sign of the Seebeck coefficient from $n$ to $p$ type depending on the doping level and temperature. The figure of merit, ZT, of the optimum SWCNT doped $\mathrm{Bi}_{2} \mathrm{Te}_{3}$ was increased by $25 \%-40 \%$ over a wide temperature range compared to the undoped sample. (C) 2012 American Institute of Physics. [http://dx.doi.org/10.1063/1.4737898]
\end{abstract}

Thermoelectric materials can be used for both cooling and electric power generation. Bismuth telluride, $\mathrm{Bi}_{2} \mathrm{Te}_{3}$, and its alloys are known to be the excellent thermoelectric materials around room temperature. ${ }^{1-3}$ They can be used in several applications, such as energy conversion, thermal sensors, thermoelectric coolers for laser diodes, etc. ${ }^{4-6}$ The performance of thermoelectric devices is determined by a figure of merit $(Z T)$, given by $Z T=\left(S^{2} \sigma / \kappa\right) T$, where $S$ is the Seebeck coefficient, $\sigma$ is the electrical conductivity, and $\kappa$ is the thermal conductivity, which contains contribution from electrons and phonons. Therefore, a material with a high $Z T$ depends on the combination of a high power factor $\left(S^{2} \sigma\right)$ and a low thermal conductivity $\kappa$. Many efforts have been made to further increase the $\mathrm{ZT}$ of $\mathrm{Bi}_{2} \mathrm{Te}_{3}$ or its alloys in nanocomposites, ${ }^{7-10}$ superlattices, ${ }^{11-13}$ and bulk materials. ${ }^{14-18}$ Although high ZT values were achieved in superlattice structures, bulks with improved ZT are ideal for large-scale energy-conversion applications due to their high efficiency of heat transfer and low cost. Enhancing ZT in $\mathrm{Bi}_{2} \mathrm{Te}_{3}$ bulk materials by several possible methods has been reported, such as the use of a nanocomposite approach ${ }^{7,19}$ and melt spinning. ${ }^{20}$ Addition of nanopowders in bulk materials is also an effective approach for improving the thermoelectric efficiency of bulk materials. ${ }^{21,22}$ It has been reported that nanopowders of insulators, semiconductors, and metals, or nanosized cavities, can introduce crystal defects and increase the density of grain boundaries, causing strong scattering of long wavelength phonons and therefore, reducing the lattice thermal conductivity. Zhao et $a .^{23}$ reported that the addition of $\mathrm{SiC}$ nanopowders resulted in a remarkable decrease in the thermal conductivity and improvement of mechanical properties of $\mathrm{Bi}_{2} \mathrm{Te}_{3}$-based alloys, leading to an increase of the figure of merit. However, $\mathrm{SiC}$ is an insulator, which may be detrimental to the electrical conductivity of bulk samples.

\footnotetext{
a)Electronic mail: xiaolin@uow.edu.au.

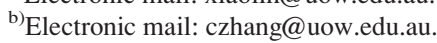

As is well known, single-walled carbon nanotubes (SWCNTs) exhibit a very high electrical conductivity at room temperature due to their very large mobility. ${ }^{24}$ This material also shows excellent thermoelectric properties because of its nanoscale, low dimensional, and holey structural features. ${ }^{25}$ Our motivations for this work on improving the thermal performance of $\mathrm{Bi}_{2} \mathrm{Te}_{3}$ by adding SWCNTs are based on the following considerations: (i) an increase in the density of states near the Fermi level is possible; (ii) both inclusions in SWCNTs and the local defects at the interface between SWCNTs and $\mathrm{Bi}_{2} \mathrm{Te}_{3}$ can result in additional lattice scattering. This implies that if a small quantity of single walled carbon nanotube can be embedded into the $\mathrm{Bi}_{2} \mathrm{Te}_{3}$ grains, the lattice thermal conductivity may decrease, while simultaneously maintaining the high electrical conductivity. In this paper, we investigate the electronic structure and the electrical/thermo transport properties of undoped and doped $\mathrm{Bi}_{2} \mathrm{Te}_{3}$ samples.

In materials preparation, $N$-type $\mathrm{Bi}_{2} \mathrm{Te}_{3}$ powders were ball-milled without any medium. The ball-milling process was carried out for $4 \mathrm{~h}$ with a rotation speed of $600 \mathrm{rpm}$ under air. As a carbon source, carbon nanotubes are predicted to be metallic or semiconducting depending on their diameter and the helicity of the arrangement of graphitic rings in their walls. Different structures and diameters will result in different electronic properties. In the present study, SWCNTs (Aldrich, $>90 \%, 0.7-1.4 \mathrm{~nm}, 0.5-2 \mu \mathrm{m}$ ) were mixed with $\mathrm{Bi}_{2} \mathrm{Te}_{3}$ after ball-milling. The doping concentrations of SWCNTs in the samples in this study were $0.5 \%, 1 \%$, and $5 \mathrm{wt}$. \%. They are denoted as samples $\mathrm{A}, \mathrm{B}$, and $\mathrm{C}$, in the following context, respectively. The powders were carefully mixed by grinding in a mortar and then pressed into rectangular bars $18 \times 3 \times 1.5$ $\mathrm{mm}^{3}$ in size. All samples were sintered at the temperature of $520^{\circ} \mathrm{C}$ for $6 \mathrm{~h}$ under high-purity argon gas prior to cooling to room temperature. Undoped $\mathrm{Bi}_{2} \mathrm{Te}_{3}$ samples made from ballmilled powders were also fabricated for comparison using the same sintering process.

The crystal structures and microstructures were examined by x-ray diffraction (XRD) in a Philips PW1730 Model 
diffractometer using $\mathrm{Cu} \mathrm{K} \alpha$ radiation $(\lambda=1.541838 \AA$ ) and transmission electron microscopy (TEM; JOEL $3000 \mathrm{~F}$, operation at $300 \mathrm{kV}$ ). The XRD patterns were collected over a $2 \theta$ range from $10^{\circ}$ to $80^{\circ}$ with a step size of $0.02^{\circ}$. TEM samples were prepared using an FEI dual beam focused ion beam (FIB) and the ex-situ lift-up technique. Electrical and thermal conductivity, the Seebeck coefficient, and the magnetoresistance were measured over a wide range of temperature from $2 \mathrm{~K}$ to $340 \mathrm{~K}$ in fields up to $13 \mathrm{~T}$ using a quantum design physical properties measurement system (PPMS).

In Figure 1(a), we show the XRD patterns of the singlewall carbon nanotube (SWCNT) doped and undoped $\mathrm{Bi}_{2} \mathrm{Te}_{3}$ samples. All samples seem to be well-developed $\mathrm{Bi}_{2} \mathrm{Te}_{3}$ single phase. According to our Rietveld refinement, the lattice parameters for samples A, B, C, and the undoped reference sample are $4.357(\AA), 4.357(\AA), 4.266(\AA)$, and $4.361(\AA)$, respectively. They are almost the same for the undoped and the SWCNT doped samples. This implies that the SWCNTs did not substitute into the crystal lattice of $\mathrm{Bi}_{2} \mathrm{Te}_{3}$, but can be embedded in grains and the matrix formed by $\mathrm{Bi}_{2} \mathrm{Te}_{3}$ the grains, as shown in Fig. 1(b). From the single electron diffraction pattern shown in the inset in Fig. 1(b), we can see that the individual grains in the doped sample show good
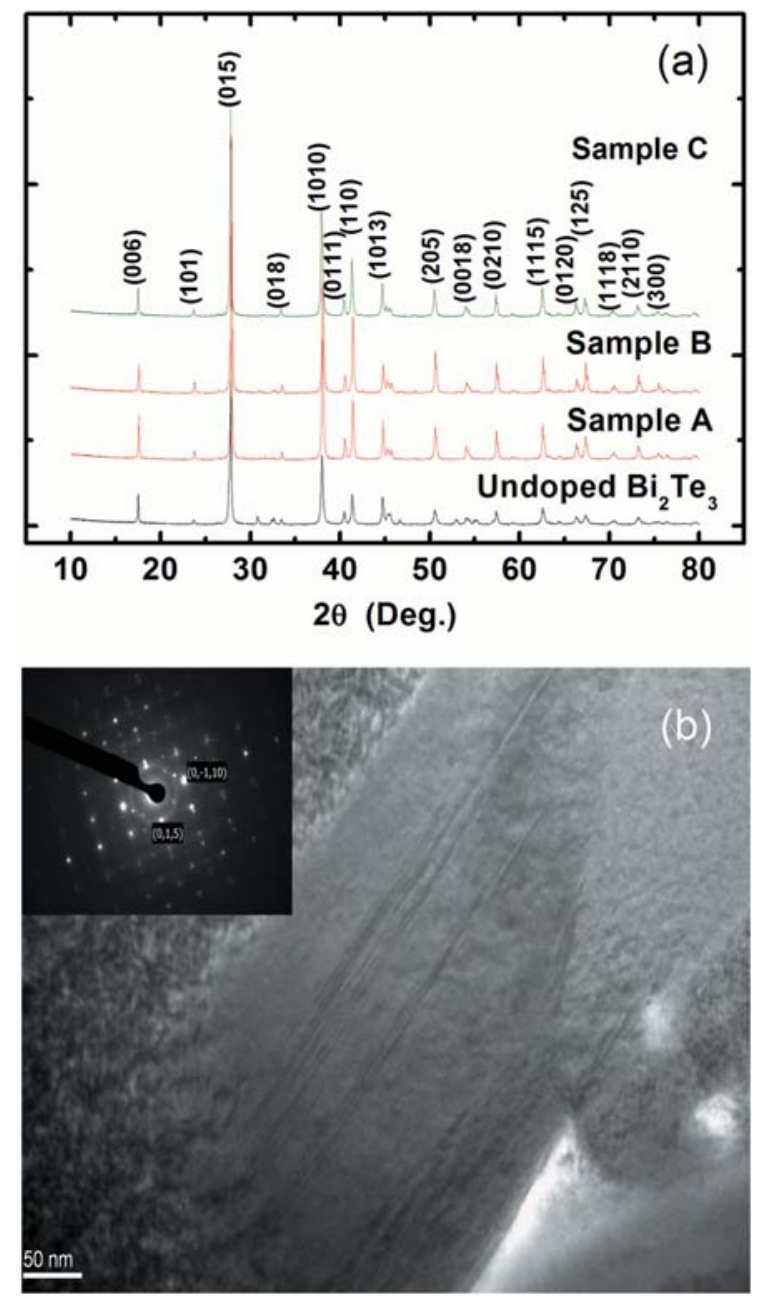

FIG. 1. XRD and TEM analysis of undoped and SWCNT doped $n$-type $\mathrm{Bi}_{2} \mathrm{Te}_{3}$ samples: (a) X-ray diffraction patterns; (b) microstructure of $0.5 \%$ SWCNT doped sample. Inset: corresponding SAED pattern of $0.5 \%$ SWCNT doped sample. crystallinity, despite the reduction in their sizes, implying that good electric conductivity is retained at least inside individual grains. Therefore, the grain boundaries and inclusions of SWCNTs should be the dominating factor controlling both the overall electric and the thermal conductivity. For SWCNT doped samples A, B, and C, however, the $c$ lattice parameter is $30.45(\AA), 30.46(\AA)$, and $30.46(\AA)$, respectively, being slightly greater than the one of the undoped sample with $c=30.37(\AA)$.

The experimental data of the thermal conductivity, electrical resistivity, Seebeck coefficient, and ZT are shown in Figure 2. As expected, the thermal conductivity is reduced greatly by incorporating the nano-sized SWCNT particles into the matrix of $\mathrm{Bi}_{2} \mathrm{Te}_{3}$ through enhancement of phonon scattering. The thermal conductivity, $\mathrm{K}$, at room temperature is about $1.38 \mathrm{~W} \mathrm{~K}^{-1} \mathrm{~m}^{-1}$ for the undoped $\mathrm{Bi}_{2} \mathrm{Te}_{3}$, and it is reduced to $1.20 \mathrm{~W} \mathrm{~K}^{-1} \mathrm{~m}^{-1}$ for $0.5 \%$ doping. The $\mathrm{K}$ for both the $0.5 \%$ and the $1 \%$ doped samples remains lower than for the undoped sample between 100 and $300 \mathrm{~K}$, as shown in Figure 2(a). This indicates that the thermal conductivity was efficiently restrained by the inclusions of SWCNTs and nano-defects induced by the SWCNTs. However, a high doping level (5 wt. \%) raises the thermal conductivity, owing to the extraordinary thermal conductivity from the SWCNTs.

The resistivity curves shown in Figures 2(b) reveals that SWCNT doping can enhance scattering for both charge carriers and lattice vibrations/phonons. The undoped sample

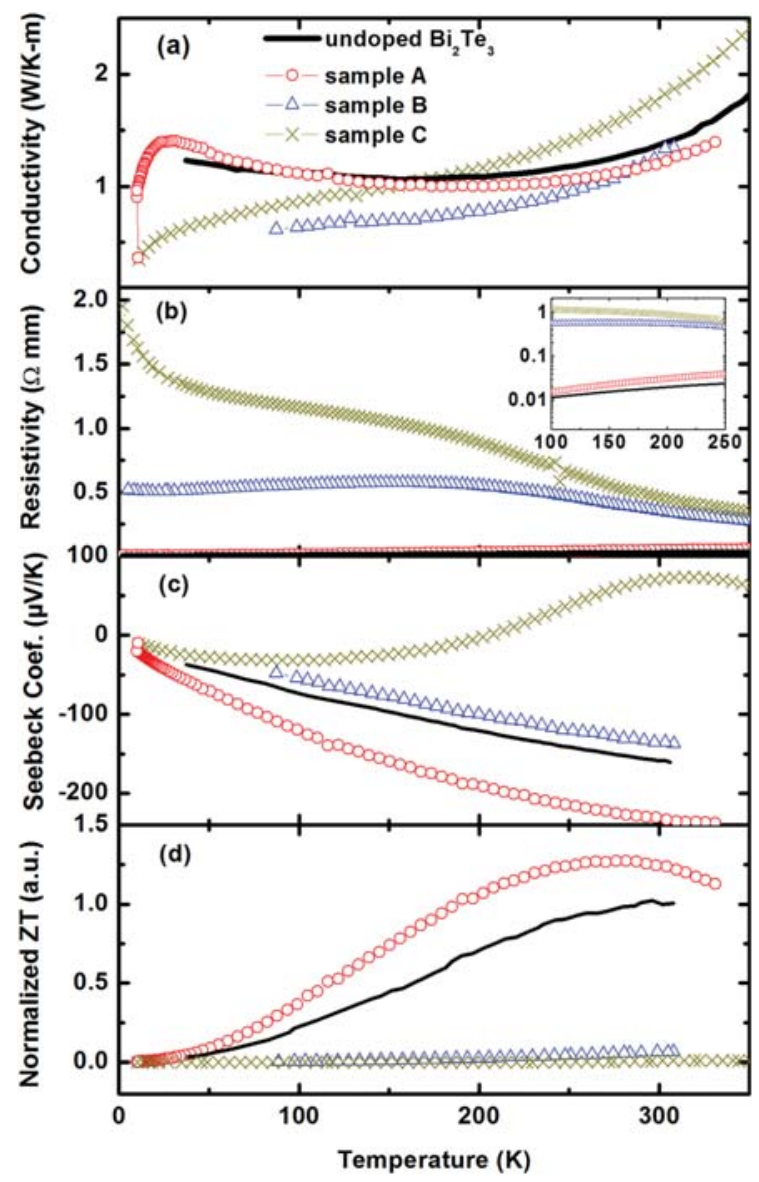

FIG. 2. Temperature dependence of (a) the thermal conductivity, (b) the resistivity, (c) the Seebeck coefficient, and (d) the normalized ZT for SWCNT doped and undoped samples. 
shows typical metallic behaviour, with resistivity of 0.025 $\Omega \cdot \mathrm{mm}$ at room temperature. $0.5 \%$ SWCNT doping slightly increases the resistivity to $0.05 \Omega \cdot \mathrm{mm}$ at the same temperature. However, the higher doping levels raise the resistivity to $0.375 \Omega \cdot \mathrm{mm}$ and $0.4 \Omega \cdot \mathrm{mm}$ for both the $1 \%$ and the $5 \%$ doped samples. It should be noted that the $1 \%$ doped sample shows a metal-insulator (MI)-like transition at $200 \mathrm{~K}$, while the $5 \%$ doped sample exhibits a sudden increase in resistivity for $\mathrm{T}<5 \mathrm{~K}$. This metal-insulator transition has not been observed in any other bulk $\mathrm{Bi}_{2} \mathrm{Te}_{3}$ reported so far. Furthermore, both the $1 \%$ and the $5 \%$ doped samples have similar values of resistivity between 250 and $390 \mathrm{~K}$, as indicated in the inset of Fig. 2(b). The non-monotonic temperature dependence in this doping range is due to the interplay of two different transport mechanisms: (i) The intra-grain transport is mainly diffusive and dominates the low temperature regime. This diffusive transport is weakly metallic. (ii) As the temperature increases, inter-grain transport becomes more dominant. The inter-grain transport is over-the-barrier (grain boundary) activation type transport. When the doping concentration is higher than $5 \%$, the electrical resistivity of the sample increases as the temperature decreases. The sample changes into a semiconductor under heavy doping.

In addition to the reduction of thermal conductivity by SWCNT doping, it is remarkable that the SWCNT doping also shows significant effects on both the type of charge carriers and on the magnitude of the Seebeck coefficient, as shown in Fig. 2(c). The undoped $\mathrm{Bi}_{2} \mathrm{Te}_{3}$ is $n$-type with a Seebeck coefficient, $\mathrm{S}$, of $\sim 140 \mu \mathrm{V} / \mathrm{K}$, in agreement with that of the $n$-type $\mathrm{Bi}_{2} \mathrm{Te}_{3}$ bulks reported so far. ${ }^{26} 0.5 \%$ SWCNT doping significantly increases $\mathrm{S}$ up to $\sim 231.2 \mu \mathrm{V} / \mathrm{K}$, being the highest value among all the $n$-type $\mathrm{Bi}_{2} \mathrm{Te}_{3}$ bulk samples reported so far. However, $1 \%$ doping reduces $\mathrm{S}$ down to $\sim 135.8 \mu \mathrm{V} / \mathrm{K}$. It is interesting to note that the sign of $\mathrm{S}$ changes from negative to positive $(\sim+71.8 \mu \mathrm{V} / \mathrm{K}$ at $300 \mathrm{~K})$ for $5 \%$ SWCNT doping for $\mathrm{T}>\sim 200 \mathrm{~K}$. It should be noted that the positive $\mathrm{S}$ of $\sim 71.8 \mu \mathrm{V} / \mathrm{K}$ at $300 \mathrm{~K}$ is much greater than that of SWCNT, which has a $\mathrm{S}$ of $\sim+30 \mu \mathrm{V} / \mathrm{K}$ at $300 \mathrm{~K}^{27}$ This means that SWCNT doping can tune $\mathrm{Bi}_{2} \mathrm{Te}_{3}$ from $n$ to $p$ type. As we expected, the $\mathrm{ZT}$ of $\mathrm{Bi}_{2} \mathrm{Te}_{3}$ has been enhanced by the SWCNTs at the optimum doping level of 0.5 wt. $\%$. The ratios of the ZT enhancement, normalized by the value for the undoped sample, are shown in Fig. 2(d). It can be seen that the $0.5 \%$ SWCNT doped sample has a larger $\mathrm{ZT}$ value than the others, and the $\mathrm{ZT}$ is enhanced by $20 \%-35 \%$ over a wide temperature range from low temperature up to room temperature.

Apart from enhancing thermoelectric properties, SWCNT doping gives rise to another remarkable feature in the $n-\mathrm{Bi}_{2} \mathrm{Te}_{3} . \mathrm{Bi}_{2} \mathrm{Te}_{3}$ exhibits a giant and positive magnetoresistance $(\mathrm{MR})$ in the $0.5 \%$ SWCNT doped sample at the low temperature of $2 \mathrm{~K}$. The MR measured at $2 \mathrm{~K}$ (shown in Fig. 3) for the $0.5 \%$ doped sample is greater than for all the other samples, with MR over $110 \%$ at $13 \mathrm{~T}$. It should noted that the undoped sample has a MR of $60 \%$, while the MR for the $1 \%$ and $5 \%$ doped samples is reduced to $20 \%$ to $30 \%$. The temperature and field dependence of MR depends on the transport regime. MR is sensitive to disorder and electron interactions and, unlike resistivity, can provide not only the temperature dependence of relevant scattering mechanisms,

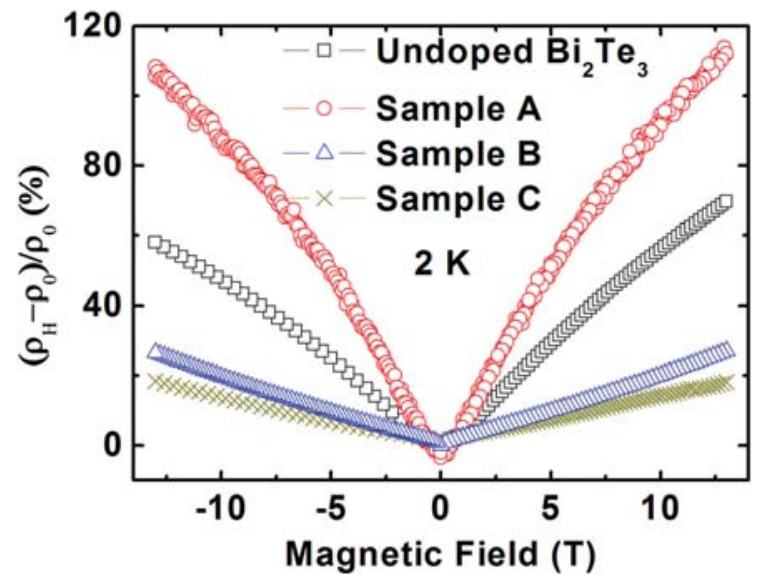

FIG. 3. Normalized magnetoresistance $[\rho(\mathrm{H})-\rho(0)] / \rho(0)$ vs. field for doped and undoped $\mathrm{Bi}_{2} \mathrm{Te}_{3}$.

but also the corresponding length scales. It is believed that the grain boundaries play a key role in electron scattering in our SWCNT doped samples. Furthermore, the trend in MR as a function of the SWCNT content is the same as that of the Seebeck coefficient. Our results on electrical, thermal, and MR properties indicate that there is a qualitive difference between the low and high doping levels. Under low doping concentrations, the electronic structure of the host material is unaffected, as indicated by the high crystallinity seen in TEM. CNTs act as additional scattering centres which only affect the transport properties. This has led to enhancement of both electrical and thermal resistivity, as well as of the thermal power. Heavy doping can lead to band structure variations and distortion of the density of states near the Fermi level, which, in turn, causes an entirely different temperature dependence of both the Seebeck coefficient and the MR, or a possible MI transition.

In summary, SWCNT doping into $n$-type $\mathrm{Bi}_{2} \mathrm{Te}_{3}$ can effectively enhance the thermal power to as high as $\sim 231 \mu \mathrm{V} / \mathrm{K}$ and reduce the thermal conductivity, as well as producing giant magnetoresistance of over $110 \%$ at low temperature in high field. The sign of $\mathrm{S}$ for $n$-type $\mathrm{Bi}_{2} \mathrm{Te}_{3}$ can be tuned from $n$ to $p$ type, depending on the SWCNT concentration. Low SWCNT $(0.05 \%)$ doped Bi2Te3 has the potential to enhance the performance of $\mathrm{Bi} 2 \mathrm{Te} 3$-based thermoelectric devices; an increase of around $25 \%$ in ZT can result in an improvement of the thermodynamic efficiency of the thermoelectric modules by around $10 \%-15 \%$ depending on the operating temperature.

The authors thank Dr. T. Silver, Dr. X. Xu, Dr. W. X. $\mathrm{Li}$, and Mr. C. Kong for their helpful discussions. This work is supported by an International Science Linkage Grant (Grant No.: CG130081).

${ }^{1}$ D. A. Wright, Nature 181, 834 (1958).

${ }^{2}$ H. J. Goldsmid, Semiconductors and Semimetals (Academic, 2000), Vol. 69 , Ch. 1.

${ }^{3}$ L. A. Kuznetsova, V. L. Kuznetsov, and D. M. Rowe, J. Phys. Chem. Solids 61, 1269 (2000).

${ }^{4}$ G. Chen, M. S. Dresselhaus, G. Dresselhaus, J. P. Fleurial, and T. Caillat, Int. Mater. Rev. 48, 45 (2003).

${ }^{5}$ L. E. Bell, Science 321, 1457 (2008).

${ }^{6}$ S. B. Hyun and X. L. Ma, Appl. Therm. Eng. 23, 913 (2003). 
${ }^{7}$ B. Poudel, Q. Hao, Y. Ma, Y. C. Lan, A. Minnich, B. Yu, X. Yan, D. Wang, A. Muto, D. Vashaee, X. Y. Chen, J. M. Liu, M. S. Dresselhaus, G. Chen, and Z. Ren, Science 320, 634 (2008).

${ }^{8}$ J. Jiang, L. D. Chen, S. Q. Bai, Q. Yao, and Q. Wang, Scr. Mater. 52, 347 (2005).

${ }^{9}$ G. Zhang, Q. Yu, W. Wang, and X. Li, Adv. Mater. 22, 1959 (2010).

${ }^{10}$ Y. Zhao, J. S. Dyck, B. M. Hernandez, and C. Burda, J. Phys. Chem. C 114, 11607 (2010).

${ }^{11}$ G. Chen, Phys. Rev. B 57, 14958 (1998).

${ }^{12}$ T. Koga, S. B. Cronin, M. S. Dresselhaus, J. L. Liu, and K. L. Wang, Appl. Phys. Lett. 77, 1490 (2000).

${ }^{13}$ G. H. Zeng, J. H. Bahk, J. E. Bowers, H. Lu, A. C. Gossard, S. L. Singer, A. Majumdar, Z. X. Bian, M. Zebarjadi, and A. Shakouri, Appl. Phys. Lett. 95, 083503 (2009).

${ }^{14}$ N. Mingo, D. Hauser, N. P. Kobayashi, M. Plissonnier, and A. Shakouri, Nano Lett. 9, 711 (2009)

${ }^{15}$ W. Kim, S. L. Singer, A. Majumdar, J. M. O. Zide, D. Klenov, A. C. Gossard, and S. Stemmer, Nano Lett. 8, 2097 (2008).

${ }^{16}$ M. Zebarjadi, G. Joshi, G. H. Zhu, B. Yu, A. Minnich, Y. Lan, X. W. Wang, M. Dresselhaus, Z. F. Ren, and G. Chen, Nano Lett. 11, 2225 (2011).
${ }^{17}$ K. F. Hsu, S. Loo, F. Guo, W. Chen, J. S. Dyck, C. Uher, T. Hogan, E. K. Polychroniadis, and M. G. Kanatzidis, Science 303, 818 (2004).

${ }^{18}$ Y. Pei, X. Shi, A. LaLonde, H. Wang, L. Chen, and G. J. Snyder, Nature 473, 66 (2011).

${ }^{19}$ Y. Ma, Q. Hao, B. Poudel, Y. C. Lan, B. Yu, D. Z. Wang, G. Chen, and Z. F. Ren, Nano Lett. 8, 2580 (2008).

${ }^{20}$ X. F. Tang, W. J. Xie, H. Li, W. Y. Zhao, and Q. J. Zhang, Appl. Phys. Lett. 90, 012102 (2007).

${ }^{21}$ J. L. Cui, L. D. Mao, W. Yang, X. B. Xu, D. Y. Chen, and W. J. Xiu, J. Solid State Chem. 180, 3583 (2007).

${ }^{22}$ X. B. Zhao, X. H. Ji, Y. H. Zhang, T. J. Zhu, J. P. Tu, and X. B. Zhang, Appl. Phys. Lett. 86, 062111 (2005).

${ }^{23}$ L. D. Zhao, B. P. Zhang, J. F. Li, M. Zhou, W. S. Liu and J. Liu, J. Alloys Compd. 455, 259 (2008)

${ }^{24}$ T. W. Ebbesen, H. J. Lezec, H. Hiura, J. W. Bennett, H. F. Ghaemi, and T. Thio, Nature 382, 54 (1996).

${ }^{25}$ I. Kunadian, R. Andrews, M. P. Menguc, and D. Qian, Carbon 47, 589 (2009).

${ }^{26}$ L. D. Zhao, B. P. Zhang, J. F. Li, H. L. Zhang, and W. S. Liu, Solid State Sci. 10, 651 (2008).

${ }^{27}$ J. W. Jiang, J. S. Wang, and B. W. Li, J. Appl. Phys. 109, 014326 (2011). 